\title{
Cultural Implication of Dragon Pattern Decorations in Kaifeng Shan-Shaan-Gan Guild Hall Buildings
}

\author{
Yinglin Zhao \\ Henan Institute of Engineering \\ Zhengzhou, China 451191
}

\begin{abstract}
Chinese special cultural beliefs created different kinds of Chinese folk art subjects, auspiciousness culture as a creative folk art creative form which has a strong concept, especially the dragon culture and dragon decorative patterns are widespread in thousands of years. Kaifeng Shan-Shaan-Gan Guild Hall is a dragon world which exist more than 300 dragon patterns in various forms.
\end{abstract}

Keywords-auspiciousness culture; dragon culture; dragon patterns in hall

\section{INTRODUCTION}

Kaifeng Shan-Shaan-Gan Guild Hall is a association of fellow provincials in Kaifeng built on the former site of $\mathrm{Xu}$ ' House in 1765 (30th years of Qianlong). The wealthy businessman from Shanxi, Shanxi and Gansu raised their money to build this hall. The Hall has majestic buildings, rigorous layout, exquisite carving for architectural ornament, it is an architectural treasure with the carving collection of wood, brick and stone.

During the architectural ornament carvings, auspiciousness pattern is a rare art treasure. The content is not about religion or superstition, most themes express owner's good intentions, related with "Fu,Lu, Shou, Xi, Cai, Ji"("Happy, Emolument, Long life, Joy, Lucky "). The "Fu" patterns in the hall are mostly photos together with bats, clouds, Sun, Dragon, Phoenix, crane, fairy, birds, flowers and jewel. They symbolize people's strong desire for a better society, peaceful time, happy family and happy life ; "Lu" patterns use more like horse, monkey and others to symbolize people's pursuit and longing for high position and handsome salary; "Shou" patters use more auspiciousness patterns with crane, Chinese bulbul, God deer, mountains, pine, peach together to symbolize people's beautiful desire for immortality and longevity; "Xi" patters uses auspiciousness patterns like magpies, Lotus, kylin, multiseed-plant pomegranate, longan, litchi, walnut. In addition to the general sense of happy things, new born child is also the huge happy thing for ancient people; "Cai" patterns use auspiciousness patterns mostly like catfish, carp, old coins series, three-legged toad, they are a decorative sublimation of people's psychology of live and work in peace, and the pursuit of wealth; "Ji" patterns use auspiciousness patterns mostly like all kinds of peony flowers, lily, apricot, hydrangea, lotus, chrysanthemum, plum with various forms of vases, meaning good luck, wealth and well-being, reunion and getting along very well.
Every nation has its own culture and belief. For thousands of years Chinese special cultural belief created different kinds of Chinese folk art subjects, auspiciousness culture as a creative folk art creative form which has a strong concept, almost all of the folk art have the pursue to the "auspiciousness".

\section{AusPiciousness CUlture}

Ji: kind and beauty; Xiang: happy and benefit. Auspiciousness Culture is a part of traditional Chinese culture which has the positive significance, it is the external reflection of Chinese people's positive psychology of love life, strive to create a happy, peaceful, wealthy life. Auspicious festive, longevity and peace are the unchangeable desire and pursuit of our nation.

Auspiciousness pattern is a unique artistic technique which Chinese people use a specific pattern to express abstract ideals, wishes and feelings. Through the ages, auspiciousness patterns can always reflect the spirit of the times and the national spirit, use auspiciousness patterns this most intuitive art form to express people's wishes and ideology, and meet the psychological demands of people pursue good fortune and avoid disaster. auspiciousness patterns are everywhere, the woodcarving, stone carving and brick carving on the residential building framework, all kinds of furniture, decorative objects of interior decoration and even paper cutting, new year paintings and clothes all have auspiciousness patterns .

In people's living demands, those with survive as its core always calling for the Naji consciousness from the deep of their lives, so auspiciousness mostly means weddings and marriage, children descent, longevity, succeed in the government examination, win promotion and get rich, good weather for the crops, a good harvest and so on. But in Chinese traditional auspiciousness culture also bears an important emotion - the dragon culture, for every Chinese people, the image of the dragon is a symbol, a mood, what is more, a flesh and blood emotion.

\section{Dragon CUlture}

Dragon is a symbol of China, also is a symbol of the Chinese nation and Chinese culture. Chinese People call themselves "The children of the Dragon", "The descendants of the Dragon" to express their love and worship to the dragon, 
Chinese people are proud of it. The Chinese people who live abroad feel more proud for this name, in the most significant places of Chinese district often have dragon symbols, so that people will know it is Chinese district only after a glance. Therefore, China is a "Country of Dragon", Chinese people are "descendants of the dragon".

In China, dragon pattern is an artistic auspiciousness pattern which has the most widely distributed area and is most well-known. Speaking of dragon, it is hard to explain with single sentence. Because the image of the dragon not only contains legend imagine component, but also by reflected by the change of dynasties, vicissitudes of life and social development, all of these reflected in the arts and design and they are constantly evolving, "Chinese Dragon" after at least seven or eight thousand years evolution, it emerged today's form. It embodies the advantages of Chinese alligators, snakes, turtles and other aquatic as the main body, and eventually formed the "Chinese dragon" image in Ming and Qing Dynasties.

Under the domination of the feudal imperial power, dragon pattern has always represented a kind of authority, it symbolize the supreme imperial power and become the representative and the incarnation of the emperor. But with the evolution of history, dragon patterns is deeply rooted among the people, as an auspiciousness incarnation, it has gradually been allowed to apply to all types of folk art forms. Chinese traditional residential buildings have many applications, the wood carvings, stone carvings, brick carvings, paintings and building components in Kaifeng Shan-Shaan-Gan Guild Hall, stone, the most common auspiciousness patterns are the "dragon patterns."

\section{DRAGON PATTERNS IN THE HALL}

Kaifeng Shan-Shaan-Gan Guild Hall has majestic buildings and cornices cross with each other, it is an architectural treasure with the carving collection of wood, brick and stone. It is a beautifully designed with rigorous layout monument. The auspiciousness culture it contains is a national treasure, the entire hall is a dragon world which exist more than 300 dragon patterns in various forms.

The "Dragon patterns" in the hall are varied and colorful. Depending on the detailed shape of the dragons, they can be divided into: Tuan long (dragon's head and tail intersect to form floral image), Li long (dragon coiled on top of some kind of object, mostly as a image of dragon playing with the pearl), Xing Long (Dragon walk with four feet), Xiang long (dragon fly in the sky) and the like; according to the environment where the dragon are, they can be divided into Cloud dragon, Sea dragon, Flower dragon, Fire dragon, etc; according to different combination with animals, there are Long Feng Cheng Xiang (a dragon and a phoenix playing toward each other, dragon symbolizes the male, phoenix symbolizes the female so it means the harmony between Yin and Yang), Long Lin Cheng Xiang (constitute with the dragon, kylin, clouds and Chinese parasol) and the like.

\section{A. Erlongxizhu (Two Dragons Play with A Pearl)}

"Dragon" is the most widely used pattern in Chinese ancient buildings, it is the highest level decorative pattern. In ancient mythology, dragon is a magical creature which can call for could and rain. People carved dragon patterns in the building with the highest level, aimed at conquering "Fire god", subduing "Water god", relieving drought, striking a good luck. Visitors of Kaifeng Shan-Shaan-Gan Guild Hall just pay a little attention, they will find almost every dragon carvings the dragon must go with the ball. Well, what is this "pearl"?

The stone picture of "Donggong Canglong Xingzuo" which kept in Nanyang Han painting consisted of a very vivid dragon, eighteen stars and a moon engraved with rabbit and toad. This dragon is the sign of the whole dragon constellation. Above the dragon head there is a bright moon, indicating the moon passes near the dragon constellation, about to enter the Spica. In Han Dynasty at the beginning of the year, the moon is rising between the two corners of the Canglong, so the Canglong and moon forged a bond. Chinese character for "Long" is consistent with the "month" and "Dragon" two radicals, its intention meaning is the moon, so it is sometimes called "Luminous Pearl", however, the dragon playing with a pearl, the pearl originally means moon, using in the temples and palaces does not match the meaning of "masculine femininity" in ancient discrepancies, and the sun out of the East, so later the pearl changed from "moon pearl" into "sun pearl", and the character "long" (with mouth radical) appears to compare with "Long" (with moon radical).For this reason, the pearl often painted with yellow or red color and around the pearl add a flame pattern.

"Dragon play with a pearl," the first mostly is single dragon play with a pearl, later according to the symmetrical beauty demand of building pattern for Chinese people, so "Erlongxizhu"(two dragon play with a pearl) appears, the pattern becomes more lively and full of meaning.

\section{1) Woodcarving Erlongxizhu}

Outside the hall, under the outside eaves and above the left and right architrave, four majestic golden dragons with bare fangs and brandish claws surrounded by peony and clouds, form the patterns together with peony, cloud and pearl, meaning pray for lucky and celebrate the harvest. On June 22, 1999, when General Secretary Jiang Zemin visited this stone carving "Erlongxizhu" at the east sub-room of the main hall, he appreciated it in every possible way. On the 33 centimeters wide screen carved with eye-catching "Erlongxizhu" pattern, dragon head protruding beyond the screen, use the circular engraving technique to make whole dragon with floating processing, which makes the dragon vivid alive.

Under the eaves of the east and west wing-rooms, there also a set of "Erlongxizhu" patterns, dragon and peony, cloud and trailing plant formed the pattern, thereby to replace the Queti. Peony also known as rich flower, trailing plant in the eyes of ancient people is an auspicious plant. Trailing plant in Chinese called "Man cao", "Man" and "Wan" have homophonic pronunciation, "Wan" means many. "Man" has a belt shape, belt in Chinese called "Dai" which has the same pronunciation of "generation", which means "Thousands of 
generations". Trailing plant climb as chain wrapped around shape, means continuous without stop. The whole screen means wealth and peace for thousands of generations without stop. Erlongxizhu pattern surrounded by peony, cloud and trailing plant, makes a richer and more auspicious meaning.

\section{2) Stone carving Erlongxizhu}

In the middle of the inner side of the door screen wall, it is set with a piece of stone carving Erlongxizhu. Two dragons fly toward each other, swim in the clouds up and down with a pearl in their mouths, holding a pearl with their left and right claws. The beautiful, vivid style and its high carving techniques all amazed the audience. The pearl held by the two dragons is neither a luminous pearl on behalf of moon pearl, nor the flame pearl on behalf of sun pearl, but it is a vivid spider with mouth and eyes. In ancient spider was called, "Xizi" take the "Xi" word. In Chinese myths and legends, "Xizi" is the God of joy, two dragons play with Xizi, meaning there will be happy things drop from the sky, happy things will come soon. Yet another explanation is, Xizi spin webs, which is the symbol of commercial communication and all fortune comes from outside. All these makes this "Erlongxizhu" pattern is more distinct from other dragon patterns in civil residence.

\section{B. Long Lin Cheng Xiang (Dragon and Kylin Together Represent the Auspiciousness)}

At the back side of the arch of the hall, at the east side under the "Wan Gu Liu Fang" plaque, there is a set of "Long Lin Cheng Xiang" wood carving consisting of dragons, kylins, clouds and Chinese parasol.

Dragon and kylin both are one of the "four spirits" in Chinese mythology which represent auspiciousness, they are auspicious things come in peace and prosperity times. Kylin, with kind character, bless and protect the peace, also with the meaning of praising the talent. Wang Rong's "Qushui Shixu" said, "Zumao Linzhi, Zonggu Panshi" which metaphor the talent with ability and political integrity. Dragon can make the world with good weather; cloud and Chinese parasol are the auspicious things which mean auspiciousness, peace and harmony.

The "dragon" patterns in the hall embodies a rhythm beauty, the patterns include both the shape of ideal beauty based on reality, and also have moving spirit temperament. Through the curved, straight, tough and soft of point, line and surface, connected with each other with sparse and dense arrangement and other dialectical process of artistic means, make it in an intense and dynamic situation.

\section{CONCLUSION}

Dragon art is outstanding cultural and artistic heritage which created by Chinese people from all nationalities together, it constantly moist art evergreen tree of Chinese nation, and it played a very profound and lasting impact to the world art development. The auspiciousness culture and dragon patterns of the dragon culture in Kaifeng Shan-Shaan-Gan Guild Hall which explore and analyze the folk art are the folk art treasures.

\section{REFERENCES}

[1] Luo Suqin, Li Xuan. Discussion on "Chinese Culture Aphasia" in English Teaching (2009. 6)

[2] Li Zehou,Chinese aesthetics [M], Tianjin: Tianjin Social Sciences Publishing Company, 1989.

[3] Zheng Jun, Chinese auspicious pattern design system [M], Guangxi Fine Arts Publishing Company, 1997.

[4] Guo Lianfu etc., Chinese patterns dictionary [M], Tianjin: Tianjin University Press, 1998.

[5] Liu Kuili, Zhang Xu, etc., China Folk Culture Series - wood carvings [M], Beijing: China Social Sciences Publishing Company, 2008.

[6] Wang Lidao, Chinese traditional moral image [M], Beijing: People's Fine Arts Publishing Company, 2008.

[7] Wang Wenyuan, Picture says Chinese auspiciousness [M], Beijing: Chinese Workers Press, 2008. 